\title{
Nieuwe tijden, nieuwe dokters. Competentiegericht opleiden
}

\author{
A.K. Meininger • P.P.M. Bakker
}

Samenvatting De door het Centraal College Medische Specialismen (CCMS) gemaakte keus voor competentiegericht opleiden leidt tot grote veranderingen in de wijze waarop specialisten opgeleid worden. Een arts c.q. specialist moet natuurlijk in de eerste plaats medisch vakman zijn, maar hij moet in zijn beroepsuitoefening tevens goed kunnen communiceren met de patiënt, samen kunnen werken met collega's, zijn zaken goed georganiseerd hebben, een academisch werk- en denkniveau hebben en bovenal een professional zijn. Deze veranderingen zijn vooral in gang gezet door maatschappelijke ontwikkelingen en veranderd overheidsbeleid, maar worden ook gestuurd door nieuwe onderwijskundige inzichten. Zowel landelijk als regionaal zijn met de modernisering van de medische (vervolg)opleidingen de afgelopen jaren de nodige ervaringen opgedaan. Wetenschappelijke verenigingen, opleiders en opleidergroepen zijn aan de slag gegaan met het maken van competentiegerichte opleidingsplannen, het formuleren van competentiegerichte opleidingsdoelen, het benoemen van opleidingsactiviteiten en met het ontwikkelen van toetsbeleid. In de opleidingspraktijk blijkt steeds vaker behoefte aan onderwijskundige achtergrondinformatie. In dit artikel worden enkele relevante vragen behandeld:

1. wat zijn competenties?

2. waarom competentiegericht opleiden?

\section{A.K. Meininger $(\triangle)$}

Drs. A.K. Meininger is onderwijskundige, werkzaam als hoofd Medische Vervolgopleidingen bij het Wenckebach Instituut van het UMCG te Groningen en lid van de Begeleidingscommissie Beschrijving Opleidingsplannen Vervolgopleidingen (BBOV).Correspondentieadres:Drs. A.K. Meininger, Wenckebach Instituut, UMCG, Postbus 11.119, 9700 CC Groningen; tel.: 050-3617003, email: a.k. meininger@wenckebach.umcg.nlBelangenconflict: geen gemeld.Financiële ondersteuning: geen gemeld.
3. wat is competentiegericht opleiden?

4. hoe gaat competentiegericht opleiden in de praktijk?

\section{Inleiding}

Maatschappelijk gezien is er niet alleen steeds meer aandacht voor de kwaliteit van de medische zorg, maar ook voor die van de medische vervolgopleidingen. ${ }^{1}$ Inhoud van de opleiding en wensen van de assistent in opleiding tot specialist (aios) en maatschappij spelen daarbij een steeds grotere rol. De vorm van de opleidingen en de belangen van de opleiders raken wat meer op de achtergrond. In dat spanningsveld worden steeds hogere eisen gesteld aan opleiders (als coach een grotere tijdsinvestering dan als traditioneel rolmodel) en opleidingsinrichtingen (meer opleiden in minder werktijd). Daarnaast moet rekening worden gehouden met een belangrijk accent op zowel kennis als kunde (veel weten en kunnen).

We zien dat overheid en specialisten geleidelijk meer samen optrekken, bijvoorbeeld in de onderlinge samenwerkingsrelaties van het College voor Beroepen en Opleidingen in de Gezondheidszorg (CBOG), de Begeleidingsgroep Beschrijving Opleidingsplannen Vervolgopleidingen (BBOV) en het Centraal College Medische Specialismen (CCMS), met als doel gezamenlijk op een haalbare en verbeterde toekomstige opleidingsstructuur uit te komen. 


\section{Wat zijn competenties?}

Er bestaat consensus over de aanname dat competenties 'niet direct zichtbare bekwaamheden of kwalificaties' zijn. Het betreft in feite de integratie van kennis, inzicht, vaardigheden en attitude. Het gaat er om dat iemand over de persoonlijke bekwaamheid beschikt om adequaat te handelen en te leren in verschillende, vooral kritische beroepssituaties. ${ }^{2}$ In de literatuur komen we diverse definities tegen van het begrip competenties. "Competentie behoort tot de categorie begrippen die ook wel wordt aangeduid met de benaming 'wicked words' of 'fuzzy concepts'. Kenmerkend voor wicked words is dat volledige consensus over de inhoud ervan moeilijk realiseerbaar is." 3

Competenties zijn van belang voor het kunnen uitvoeren van opdrachten of vervullen van taken in een bepaalde functie of beroep. Taken worden binnen een beroepsdomein vervuld in een bepaalde context, in de vorm van activiteiten of handelingen, die tot resultaat moeten leiden (ondersteund met kenmerkende hulpmiddelen). Zie figuur $1 .^{4}$

Competenties weerspiegelen zich in een te leveren concreet resultaat (output, product) en in zichtbaar, observeerbaar concreet gedrag (procesaspecten). Gedrag en resultaat moeten met behulp van (prestatie-) indicatoren zo goed mogelijk meetbaar gemaakt worden. ${ }^{5}$ Gedrag kent procesgeoriënteerde indicatoren (bijvoorbeeld: hoe handig is een aios met 'knopen en hechten' of hoe patiëntvriendelijk is hij of zij?); resultaat kent als indicator bijvoorbeeld 'de kwaliteit van de gemaakte knopen' of 'de tevredenheid' van de patiënt. Wat een medewerker, i. c. de aios, als gedrag en resultaat daadwerkelijk laat zien op de werkvloer noemen we de 'performance'.

Competenties zijn dus contextgebonden, waarbij er een relatie is tussen iemands kwaliteiten en de taken die vervuld moeten worden. Dit leidt tenslotte tot het daadwerkelijk handelen in de specifieke beroepssituatie, de performance, dat gekenmerkt wordt door resultaten en gedrag.

Naast het medisch handelen heeft het CCMS voor de medische vervolgopleidingen de volgende competentiegebieden benoemd (kaderbesluit): communicatie, samenwerken, organisatie, maatschappelijk handelen, kennis \& wetenschap en professionaliteit. Deze competentiegebieden of zogenaamde CanMeds-rollen zijn gebaseerd op het resultaat van een grootschalig onderzoek onder de Canadese bevolking. In Canada zijn de door het Royal College of Physicians and Surgeons oorspronkelijk geformuleerde competenties in 2005 opnieuw vastgesteld. ${ }^{6}$

Momenteel zitten de meeste specialismen in de implementatiefase en wordt er in het bijzonder expliciet veel aandacht besteed aan interprofessioneel samenwerken in teamverband en leiderschap (dit valt binnen het competentiegebied samenwerken). ${ }^{7}$

\section{Waarom competentiegericht opleiden?}

Vernieuwingen van de medische vervolgopleidingen behoren voort te vloeien uit een bewuste keuze naar aanleiding van de volgende vragen:

1. waarom moet het anders?

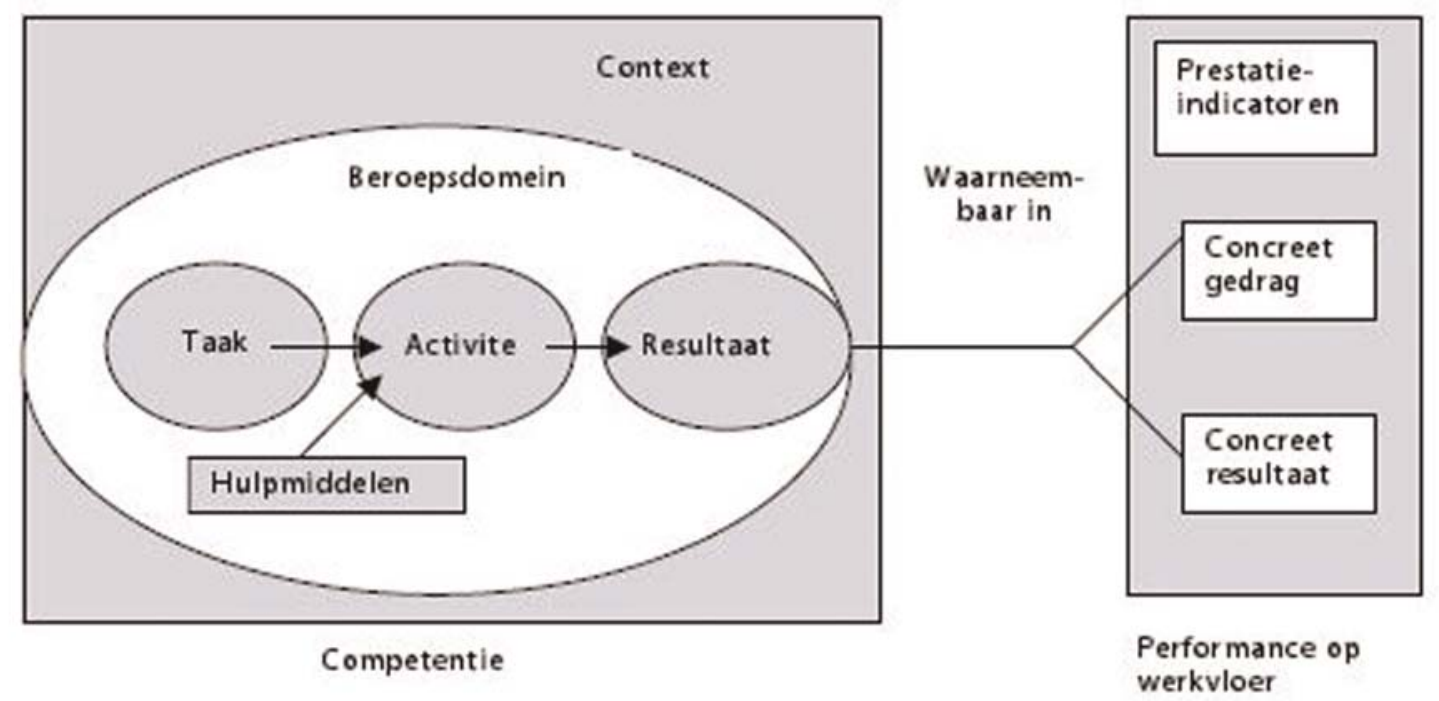

Figuur 1 Schema competentie en performance 
2. wat levert het nieuwe (competentiegerichte) opleiden eigenlijk op?

3. worden hiermee betere specialisten opgeleid?

De belangrijkste legitimatie van competentiegericht opleiden is het uitgangspunt dat opleidingen zijn afgestemd op ontwikkelingen in de maatschappij en gezondheidszorg. ${ }^{8}$

Het huidige overheidsbeleid is gericht op het stimuleren van de marktwerking binnen de gezondheidszorg. Hierdoor moeten zorginstellingen zich buigen over hun concurrentiepositie. Patiënten en patiëntenorganisaties willen nauwer betrokken zijn bij de (kwaliteit van de) patiëntenzorg (geen wachtlijsten, patiëntvriendelijkheid, zorgtrajecten etc.). Als voorbeeld kan het programma genoemd worden van de informatiemarkt "Samen bouwen aan patiëntgerichte zorg", in 2006 georganiseerd door het UMCG en Stichting Zorgbelang

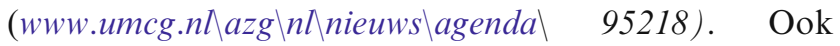
andere ontwikkelingen spelen een rol: bevolkingsopbouw (ontgroening en vergrijzing), snelle (technologische) ontwikkelingen in de geneeskunde en artsen met een andere waardering van de balans tussen werk en privé-leven. Deze ontwikkelingen leiden tot problemen op het gebied van capaciteit (tekort aan zorgprofessionals) en kwaliteit (inhoud en manier van werken; te hoge werkdruk). Daarom is een andere manier van opleiden nodig en het opleiden van 'nieuwe' professionals. Met andere woorden: nieuwe tijden vragen nieuwe dokters. De veranderingen hebben invloed op de functie en de bekwaamheden van de medisch specialist. Voorheen stond vooral de medische vakinhoud centraal. Deze inhoud blijft onveranderlijk belangrijk; alleen worden er meer taken aan toegevoegd. Van de medisch specialist wordt nu ook veel meer verwacht als het gaat om de eerder genoemde algemene competenties. Door het CCMS wordt dan ook juist het belang van de algemene competenties in de vernieuwde medische vervolgopleidingen benadrukt. In het curriculum van iedere wetenschappelijke vereniging dienen de algemene competenties voldoende te zijn geëxpliciteerd.

Hieronder volgen enkele belangrijke onderwijskundige argumenten voor het werken met competenties. ${ }^{9}$

\section{Richting geven}

Met behulp van competenties kan beter richting worden gegeven aan de gewenste ontwikkeling van lerenden, i.c. de aios. Met competentieprofielen kan beter tot uitdrukking worden gebracht wat de gewenste ontwikkelingsrichting is.
Communicatie

Het werken met competenties fungeert daarnaast als een communicatie-instrument. De competenties vormen de taal waarin doelen en verwachtingen worden geëxpliciteerd. Aios kunnen daardoor meer gericht werken aan hun eigen ontwikkeling.

\section{Verticale afstemming}

Competentiegericht werken biedt de mogelijkheid om de verwachtingen van de organisatie, in termen van het organisatiebeleid en de innovatiestrategie enerzijds en de instrumenten voor het personeelsbeleid anderzijds, beter op elkaar af te stemmen.

\section{Horizontale afstemming}

Competentiegericht werken biedt de mogelijkheid de instrumenten voor personeelsbeleid onderling beter op elkaar af te stemmen.

\section{Dynamisering}

Technologische innovatie, innovatie in de organisatie van arbeid, innovatie in producten en productieprocessen leiden tot de noodzaak van een voortdurend leerproces. De weerstand die bestaat tegen het veranderen van functieomschrijvingen gaat voor competentieontwikkeling dus niet op.

\section{Ontwikkeling}

Competentiedenken vormt een stimulans tot allerlei vormen van personeels- en organisatiebeleid; zonder doordacht personeels- en organisatiebeleid heeft competentieprofilering en -beoordeling weinig zin, zeker ook doordat veel organisaties veranderingen dienen door te voeren met het zittende personeel.

\section{Wat is competentiegericht opleiden?}

De grootste verschillen tussen de traditionele manier van opleiden en de nieuwe competentiegerichte wijze van leren en ontwikkelen binnen de medische vervolgopleidingen zijn in box 1 weergegeven.

In de opleiding tot specialist wordt met het benoemen en vaststellen van eerder genoemde competenties, de introductie van een portfolio en met voortgangsgesprekken een begin gemaakt. Hiermee krijgt de door het CCMS gemaakte keus voor competentiegericht leren en ontwikkelen gestalte. ${ }^{10}$ 
Opleiden

Globale opleidingsinhoud en doelen

Globale feedback, weinig zelfsturing, weinig coaching

Activiteiten opleider centraal

(Deel)taken, fragmentatie

Taken en verantwoordelijkheden die horen bij de functie (functieeisen)

Vooral aandacht voor vakspecifieke kennis en vaardigheden

Inhoud en vorm van de opleiding liggen in principe vast

Geen modularisering en vaste tijdsduur van de opleiding

Geen duidelijke selectie- en beoordelingscriteria

Criteria voor suspervisie erg globaal, docentrol moeilijk te beoordelen

Moeilijke inpassing van erkenning van verworven competenties; wel erkenning van verworven kwalificaties en kennis

Weinig transfer naar andere beroepen en functies

Eindtermen opleiding sluiten niet goed aan op wensen patiënt
Leren en ontwikkelen

Helder geformuleerde leerinhouden, doelen en toetsingscriteria Specifieke feedback, meer zelfsturing, meer coaching

Activiteiten aios centraal

Authentieke gehelen, integratie

Competenties, deels gerelateerd aan een functie, maar ook breder naar levensloopbaan (competentie-eisen)

Veel aandacht voor vakoverstijgende competenties: gedrag en resultaat

Dynamische leerprocessen, inhoud en vorm meer op de persoon gericht

Modularisering en variabele instap, c.q. variabele opleidingsduur Eventuele mogelijkheid iemamd wel/niet te selecteren c.q. op grond van beoordeling tijdens de opleiding af te wijzen

Duidelijke criteria voor docentrollen, beoordeling docenten in principe eenvoudiger

Eerder verworven competenties (EVC), ook op basis van attitudes en leermogelijkheden

Meer transfer naar andere beroepen en functies Eindtermen opleiding sluiten wel goed aan op wensen patiënt

\section{Box 1 Overzicht traditioneel versus competentiege- richt opleiden.}

\section{Hoe gaat competentiegericht opleiden in de praktijk?}

Door de BBOV wordt benadrukt dat authentieke situaties (de werkelijke of zogenaamde kenmerkende beroepssituaties op de werkplek) belangrijk zijn en blijven voor het ontwikkelen van competenties. Leren op de werkplek neemt dus (nog altijd) een belangrijke plaats in binnen iedere medische vervolgopleiding.

Omdat de aios ongeveer 95\% van de werk- c.q. opleidingstijd doorbrengt in de praktijk dient daar het opleiden en leren op gestructureerde wijze gestalte te krijgen.

${ }^{11}$ Het 'al doende' leren in de praktijk blijkt in de huidige bedrijfsvoering echter steeds meer belastend voor arts en patiënt en tevens vaak minder veilig voor de patiënt. Mede daarom is het leren in nagebootste, gesimuleerde situaties ('skillslabs') steeds belangrijker aan het worden. 12

Flankerend zijn tevens cursorisch onderwijs en E-learning c.q. 'web-based learning' in toenemende mate van belang. ${ }^{13-14}$

\section{Teaching on the run}

Om de rol als opleider/supervisor bij het competentiegericht opleiden in de praktijk goed te kunnen vervullen is het nodig het werk zo te organiseren dat de opleider/ supervisor de aios voldoende aan het werk ziet. Tevens is het van belang dat patiëntenzorgactiviteiten, bijvoorbeeld patiëntenbesprekingen, referaten, ochtendoverdracht, polikliniek, visites, obductiebespreking, multidisciplinair overleg etc., zoveel mogelijk als leermomenten kunnen worden benut. Op deze wijze krijgen deze traditioneel als patiëntenzorg opgevatte activiteiten de functie van opleidingsactiviteiten. Bovendien is het belangrijk dat de supervisor snel en directe feedback geeft, enerzijds om de beschikbare tijd efficiënt te benutten, anderzijds om een zo groot mogelijk effect van de feedback te bewerkstelligen. In de literatuur wordt in dit verband wel gesproken van 'Teaching on the run' ${ }^{15}$

Gestructureerde feedback: bevorderen van het leerproces

Goed opleiden is sterk verbonden met een goede vorm van beoordeling en de daaraan gekoppelde feedback. Het geven en ontvangen van gestructureerde feedback in een goede dialoog tussen opleider/supervisor en aios kan daarom als de essentie van het competentiegericht opleiden in de praktijk worden gezien. Ten eerste wordt voor de aios duidelijk wat (en hoe) er wordt beoordeeld en wat van belang is. Het heeft daardoor een sturend effect op het leren. Bij de keuze tussen verschillende onderwijsonderdelen kiest de aios vooral voor datgene wat getoetst wordt: 'Assessment drives learning'. ${ }^{16}$ Ten tweede krijgen de opleiders een helder beeld van het wat, waarom en hoe van het beoordelen en inherent hieraan een helder beeld van wat hun aios moeten leren. Dat helpt de 
opleiders zich te richten op de wijze waarop ze aan aios adequaat feedback kunnen geven.

\section{Toetsen en beoordelen}

Het doel van selectief (= summatief) toetsen is formele besluitvorming over de voortgang van de aios. Heeft de aios voldoende competenties verworven om naar het volgende deel van de opleiding over te gaan? Om verrichtingen zonder directe supervisie uit te voeren? Heeft de aios voldoende competenties verworven om als geregistreerd specialist aan de slag te gaan? De kwaliteit van toetsing en beoordeling moet voldoende zijn om zulke verreikende consequenties te verantwoorden.

Formatieve (of educatieve) en summatieve (of selectieve) beoordeling zijn te scheiden functies, maar zullen in de prak- tijk op elkaar aansluiten. In periodieke voortgangsgesprekken bespreken opleider en aios de voortgang, onder andere aan de hand van diverse beoordelingen en de zelfevaluatie van de aios. Deze voortgangsgesprekken zijn formele beoordelingen waarbij alle competentiegebieden aan de orde dienen te komen. Er moeten dan ook tevoren afspraken gemaakt worden over tijd en duur van deze gesprekken.

\section{Wie beoordeelt?}

Is het alleen de opleider die beoordeelt? Nee, de opleider is er verantwoordelijk voor dat er vaak genoeg wordt beoordeeld. Hij/zij voert zelf veelal de selectieve toetsing/beoordeling uit. Voor allerlei aspecten en onderdelen van het toetsen en beoordelen moeten ook anderen worden ingeschakeld: eigen stafleden, andere collegastafleden bij diverse stages en in sommige gevallen andere zorgverleners. Een voorbeeld van een instrument waarbij verschillende zorgverleners (bijvoorbeeld verpleegkundigen, paramedici, patiënten, collega-aios) vanuit verschillende perspectieven een waardevolle bijdrage kunnen leveren aan de beoordeling is de 360 graden (of multisource) feedback. ${ }^{17}$

Tenslotte is ook de aios zelf een belangrijke partij. Hij/ zij moet immers leren eigen vorderingen te beoordelen en eigen leerpunten te formuleren, daarbij gebruik makend van de beoordeling van anderen.

\section{Met welke instrumenten?}

Er is er niet één assessment-instrument afdoende om alle competenties te meten. ${ }^{18}$ Daarom worden voortgangsen jaargesprekken gevoerd op basis van een combinatie van informatie over competenties in de relevante beroepssituaties, afkomstig uit diverse bronnen. Bij formatieve evaluaties kan de informatie uit één of eventueel enkele instrumenten volstaan: feedback op basis van een Korte Praktijk Beoordeling (KPB) of een patiëntevaluatie. Een belangrijk aspect van het gebruik van de KPB is dat de aios geobserveerd wordt en feedback krijgt op zijn of haar functioneren in de klinische praktijk.

De supervisor observeert een gedeelte van een (patiëntenzorg)activiteit die als opleidingsactiviteit $(=$ middel $)$ wordt benut, bijvoorbeeld overdracht, poli, consult, grote visite, voordracht, etc. De supervisor geeft aansluitend maximaal tien minuten feedback. Ook deze methodiek moet aangepast worden aan de omstandigheden: de operatiekamer heeft een eigen dynamiek die verschilt van bijvoorbeeld de polikliniek. Dat vraagt om een variant op de KPB: de OSATS (Objective Structured Assessment of Technical Skills).

Het portfolio omvat de verzameling van beoordelingen die de opleider nodig heeft om voortgangs- en jaargesprekken te voeren, inclusief de resultaten van cursussen en andere onderwijsactiviteiten én de zelfbeoordeling van de aios. Het portfolio bevat bijvoorbeeld verschillende KPB's die zijn afgenomen in diverse situaties en bij verschillende patiënten en ook nog door verschillende supervisoren zijn ingevuld. Ook in andere situaties zal een aios geobserveerd kunnen/moeten worden; er worden verslagen, ontslagbrieven, documentatie van de uitgevoerde activiteiten en ook resultaten van de uitgevoerde activiteiten toegevoegd, zeker als er specifieke afspraken gemaakt worden met een aios ten aanzien van het leertraject.

De zelfbeoordeling is een vorm van reflectie die betrekking heeft op één of meer van de competenties en op de daarin bereikte niveaus. Zodoende heeft het portfolio een metafunctie. De aios schrijft deze zelfbeoordeling en brengt die in bij het voortgangs- of beoordelingsgesprek. De afspraken die gemaakt worden bij deze gesprekken worden ook weer in het portfolio vastgelegd.

\section{Aanbevelingen}

Een belangrijke verandering als gevolg van het competentiegericht opleiden tot medisch specialist is de wijze waarop opgeleid wordt. Het is niet meer alleen de 'gezel' die leert van de 'meester'. De aios krijgt juist zelf gedurende de opleiding meer invloed op het leerproces; hij/zij is hier zelfs verantwoordelijk voor. De 'meester' wordt meer 'begeleider' of 'coach'. Het gehele opleiderscollectief van een specialisme is verantwoordelijk voor een helder opleidingsbeleid en een goed leerklimaat binnen de afdeling.

Uitwisseling van ervaringen en onderzoek is nodig om de kwaliteit van het toetsen en beoordelen verder te 
ontwikkelen. In de praktijk blijken opleiders onderling niet dezelfde opvattingen te hebben over wat adequaat gedrag is. Voor een valide en betrouwbare (eerlijke) beoordeling is het belangrijk dat de beoordelaars op dezelfde wijze beoordelen.

Op de werkvloer vereist een goede uitvoering van toetsing en beoordeling dat:

1. opleiders zich ook op dit gebied scholen

2. opleiders toetsen en beoordelen inbouwen in de werkorganisatie

3. opleiders regelmatig met elkaar bespreken waarop zij hun beoordelingen eigenlijk baseren.

Een opleidingsklimaat en werkcultuur waarin onderlinge feedback en kritische zelfreflectie basale uitgangspunten zijn, zijn daarbij van doorslaggevend belang.

The decision by the Central College of Medical Specialties (CCMS) to introduce competence-based programmes for specialist training has heralded major changes in postgraduate training programmes. Of course, doctors and specialists should first and foremost be medical experts but practising medicine in a professional manner also requires good communication with patients, collaboration with colleagues, good management skills, good academic qualities and, above all, professionalism. Changes in postgraduate training have mainly been inspired by societal developments and changes in government policy but they are also directed by novel developments in education. Today, considerable experience has been gained with modernising medical (postgraduate) training both nationally and regionally. Scientific societies, programme directors and groups of programme directors have been developing plans for competence-based training programmes, formulating competence-based objectives, designing educational activities and developing assessment programmes. From the field of postgraduate clinical training there is an increasing demand for educational underpinnings competence-based training. In this article the following questions are addressed:

1. What are competencies?2. Why should specialist training be competence based?3. What is competence-based specialist training? 4. How to put competence-based training programmes into practice?
}

\section{Literatuur}

Overzicht van gebreken sinds 2004: Acht opleidingen tot specialist gestaakt. NRC Handelsblad, voorpagina, 27 januari 2007.

Spencer LM, Spencer SM. Competence at Work. New York: Johwn Wiley \& Sons, Inc.; 1993.

Merriënboer JJG van, Klink MR van der, Hendriks M. Competenties: van complicaties tot compromis: over schuifjes en begrenzers. Den Haag: Onderwijsraad; 2002.

Miniconferentie OTEC 'Het hoe en waarom van samenwerkend leren', 19 maart 2004.

AZG, Coachen op resultaat en gedrag, Maarssen: PiMedia BV; 1998.

Frank J. The CanMEDS Project Overview 2005. The Royal College of Physicians and Surgeons of Canada; 2005.

Frank J. Medical Leadership and Effective Interprofessional Health Care Teams: A Competencybased Approach. Vancouver: 2007.

Gans ROB. Inleiding Werkconferentie 'Modernisering Medische Vervolgopleidingen', 7 maart 2007. Beschikbaar op www. medischevervolgopleidingen. $\mathrm{nl}$

Mulder M. Competentieontwikkeling in bedrijf en onderwijs [inaugurele rede]. Wageningen; 2000.

MOBG. Project Modernisering Medische Vervolgopleidingen. Ontwikkeling en implementatie van een vernieuwd opleidingstraject tot medisch specialist. Utrecht, september 2005.

Norcini JJ. Workplace-based assessment in clinical training. Association for the Study of Medical Education, Edinburgh, 2007.

Issenberg SB, McGaghie WC, Petrusa ER, Gordon DL, Scalese RJ Features and uses of highfidelity medical simulations that lead to effective learning: a BEME systematic review. Med Teach 2005;27:10-28.

Borleffs JCC, Leeuwen-Seelt EI van, Meininger AK, Mens MAP. Denken, doen en delen, UMC's als regionale expertisecentra voor Onderwijs \& Opleiding, Nederlandse Federatie UMC's (NFU). Nieuwegein, 2007.

Cook DA, Dupras DM. A Practical Guide To Developing Effective Web-based Learning, JGIM 2004; 19 (6):698-707.

Lake FR, Vickery AW, Ryan G. Teaching on the Run, Med J Aust 2005; 182(3):126-7.

Thistletwaite J. More thoughts on 'assessment drives learning', Med Educ 2006; 40(11):1149- 1150.

Davies H. Work based assessment, BMJ Careers, 20-27 augustus 2005.

Epstein, RM. Assessment in Medical Education, Medical Education Review article, N Engl J 356;(4) 387-396. 